\title{
Some thoughts and strategies of planning for the impact of "COVID-19" epidemic in Yunnan plateau basin
}

\author{
Ziqian Shi, Hua Chen*, Kai Fan, Peng Chen \\ Yunnan Design Institute Group Co., Ltd., Kunming, China
}

\begin{abstract}
Combined with the big data report of Baidu epidemic, and based on the transmission route and characteristics of "COVID-19" Virus, using GIS spatial analysis technology and related mathematical models, the correspondence between the epidemic development distribution and the spatial pattern of the basin in the Yunnan Plateau was simulated, and the basin distribution, traffic accessibility, urban scale, and tourism fever were found. Destination fever is closely related to the development of the epidemic. Changing the mode of transportation in the basin, changing the mode of land use, constructing regional public health facilities, and improving the community living circle have a suppressive effect on the spread of the epidemic. According to the simulation conclusions, this article focuses on blocking the spread of the epidemic and guaranteeing the treatment and basic life of the personnel during the disaster. It proposes the considerations of the territorial space planning of the Yunnan Plateau basin in response to the epidemic from the region (province)-basin area-community and governance level.
\end{abstract}

\section{Introduction}

The outbreak of the "COVID-19" epidemic is a particularly significant public health disaster "Black Swan Incident". Through this incident, we need to carefully examine the important impact of disaster prevention and control on the compilation of land space planning, change the development strategy and revise the technical path, and change the economic supremacy, disorderly expansion, extensive and inefficient urban and rural development planning model, which is very important for the construction of a safe, resilient and green living environment. The "COVID-19" virus mainly through respiratory droplets and contact transmission, following a certain spatial transmission law, closely related to urban size, population mobility, transportation and so on ${ }^{[1]}$. Due to the geographical environment of the plateau basin in Yunnan, the distribution of epidemic situation is obviously different. Through big data and space analysis technology, we find out its rules, and put forward countermeasures and suggestions in the current land and space planning from the two aspects of blocking epidemic situation and ensuring life, which is conducive to promoting comprehensive disaster prevention and control and building a safe and resilient green living environment.

\section{Overview}

\subsection{Overview of "COVID-19" epidemic in Yunnan province}

According to the data published by the Yunnan Provincial Health Commission, As of February 21,2020 ${ }^{[2]}$, the cumulative diagnosis of new coronal pneumonia confirmed 174 cases in Yunnan, the daily average increase of confirmed cases of 18.76 percent, Kunming is the highest, reaching 14.15 percent. According to the track of 119 patients who published their exact whereabouts, 80.67 percent, of the confirmed patients were from outside the province, mainly foreign input. After February 11, it became endogenous diffusion.

\subsection{Basic conditions of Yunnan plateau basin}

The topography and geomorphology of Yunnan Province is mainly mountainous and plateau, and the basin only accounts for 6 percent of the province, and the specific quantity and area are shown in Table. $1^{[3]}$. In terms of urban size, according to the latest criteria for urban size division, there are only one large city with more than 3 million people in Kunming, one city with more than 500,000 people in Qujing, and the rest are small cities with less than 500,000 people, accounting for about $62 \%$ of the people below 100,000. In terms of traffic accessibility, referring to the air and railway mileage of the states and 
cities and the traffic location conditions, the whole Yunnan Province is divided into five grades: high, high, medium, low and low, Among them, Kunming, Yuxi, Chuxiong are high, Nujiang is low. In terms of tourist fever, referring to the amount of tourists received by the states and cities over the years, the cities of Yunnan Province are ranked as the highest tourist fever. Among them, Kunming City has the highest tourist fever, Honghe, Dali, Lijiang and other cities are higher, Dehong, Diqing, Pu'er and other places have lower tourist fever, and Nujiang Prefecture has the lowest tourist fever.

Table. 1 Distribution and area of basins in Yunnan Province (Data source: Study on basins in Yunnan Province)

\begin{tabular}{|c|c|c|}
\hline Urban & Number of basins & Area $/ \mathbf{k m}^{\mathbf{2}}$ \\
\hline Zhaotong & 127 & 1288.64 \\
\hline Wenshan & 261 & 1741.59 \\
\hline Pu'er & 126 & 955.82 \\
\hline Nujiang & 37 & 192.59 \\
\hline Lincang & 84 & 703.56 \\
\hline Lijiang & 136 & 1540.88 \\
\hline Honghe & 120 & 2041.62 \\
\hline Diqing & 81 & 834.1 \\
\hline Dehong & 65 & 1417.79 \\
\hline Dali & 116 & 2848.09 \\
\hline Yuxi & 65 & 1175.32 \\
\hline Chuxiong & 174 & 1475.41 \\
\hline Baoshan & 120 & 1761.87 \\
\hline Qujing & 176 & 3864.29 \\
\hline Kunming & 122 & 2898.86 \\
\hline Xishuangbanna & 58 & 947.23 \\
\hline Total & $\mathbf{1 8 6 8}$ & $\mathbf{2 5 6 8 7 . 6 6}$ \\
\hline
\end{tabular}

\section{Fitting the distribution of the epidemic and the plateau basin}

By means of ARCGIS, SPSS and other software, the correlation between the epidemic situation of the New Crown pneumonia in Yunnan Province and the factors such as the distribution of the basin, the city scale, the traffic accessibility and the tourist fever were analyzed. The calculation formula is as follows ${ }^{[4]}$ :

$$
r=\frac{l_{X Y}}{\sqrt{l_{X X} l_{Y Y}}}=\frac{\sum(X-\bar{X})(Y-\bar{Y})}{\sqrt{\sum(X-\bar{X})^{2} \sum(Y-\bar{Y})^{2}}}
$$

In the formula, " $r$ " is the correlation between variables, " $|\mathrm{r}|$ " indicates the degree of correlation between the two variables. " $r>0$ " denotes positive correlation, " $r<0$ " denotes negative correlation, and " $\mathrm{r}=0$ " denotes zero correlation. The degree of relevance is: " $|\mathrm{r}|$ "value $0.8 \sim 1$, strong correlation; value $0.6 \sim 0.8$, strong correlation; value $0.4 \sim 0.6$, moderate correlation; value $0.2,0.4$, weak correlation; value $0.0 \sim 0.2$, extremely weak correlation or uncorrelated.

Final correlation coefficients need to be tested by significant " $\mathrm{P}$ " values, " $\mathrm{P} \leq 0.05$ " considered significant correlation. the "*" in the correlation coefficient " $r$ " value in the analysis results indicates significant correlation at " $p \leq 0.05$ " level, " ***" indicates significant correlation of variables at " $p \leq 0.01$ " level.

\subsection{Epidemic and basin distribution}

The correlation analysis results of epidemic development and basin distribution are shown in Fig. 1 and Table. 2. The number of confirmed cases of "COVID-19" epidemic in Yunnan Province and the rate of epidemic spread have weak or no correlation with the number of basin, and there is a positive correlation with the area of basin. Overall, the larger the area, the more confirmed cases, the larger the daily average growth rate, the faster the spread of the epidemic.
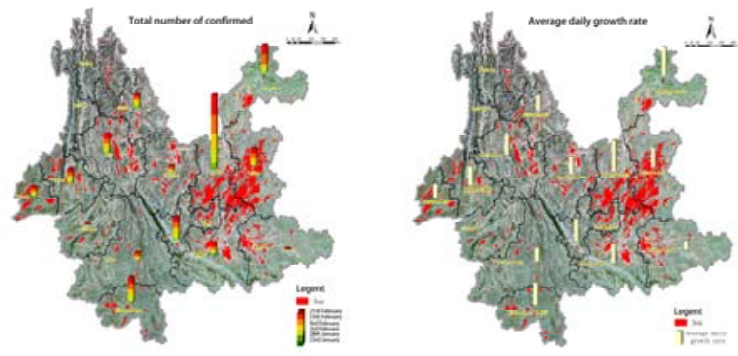

Fig. 1 Distribution of epidemic and basin

Table. 2 Correlation between epidemic development and distribution of basin

\begin{tabular}{|c|c|c|c|c|}
\hline & & \begin{tabular}{|c|} 
Number \\
of \\
basins
\end{tabular} & $\begin{array}{l}\text { Area of } \\
\text { basins }\end{array}$ & Results \\
\hline \multirow{2}{*}{$\begin{array}{c}\text { Cumulative } \\
\text { confirmed } \\
\text { cases }\end{array}$} & $\mathrm{r}$ & 0.013 & $0.515^{*}$ & \multirow{2}{*}{$\begin{array}{l}\text { There is a weak or no } \\
\text { correlation with the number } \\
\text { of basins and a moderate } \\
\text { positive correlation with the } \\
\text { area of basins }\end{array}$} \\
\hline & $p$ & 0.961 & 0.041 & \\
\hline $\begin{array}{l}\text { Average } \\
\text { daily }\end{array}$ & $\mathrm{r}$ & 0.165 & $0.597^{*}$ & \multirow{2}{*}{$\begin{array}{l}\text { There is a weak or no } \\
\text { correlation with the number } \\
\text { of basins and a moderate } \\
\text { positive correlation with the } \\
\text { area of basins }\end{array}$} \\
\hline $\begin{array}{l}\text { growth rate } \\
\text { of } \\
\text { confirmed } \\
\text { cases }\end{array}$ & $\mathrm{p}$ & 0.542 & 0.015 & \\
\hline
\end{tabular}

\subsection{Epidemic and urban scale}

The results of the correlation analysis of epidemic development and urban scale are shown in Fig. 2 and Table. 3. According to the analysis, there is a strong positive correlation between the number of confirmed cases and the rate of epidemic spread in Yunnan Province and the urban scale. Overall, the larger the size of the city, the more confirmed cases, the larger average daily growth rate, the faster the spread of the epidemic.
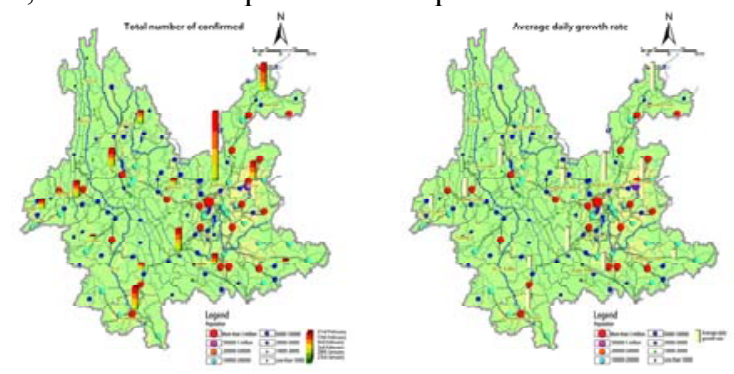

Fig. 2 Distribution of epidemic and urban scale 
Table. 3 Correlation between epidemic development and urban scale

\begin{tabular}{|c|c|c|c|}
\hline & & $\begin{array}{c}\text { Urban } \\
\text { scale }\end{array}$ & Results \\
\hline \multirow{2}{*}{$\begin{array}{l}\text { Cumulative } \\
\text { confirmed } \\
\text { cases }\end{array}$} & $\mathrm{r}$ & $0.692^{* *}$ & \multirow{2}{*}{$\begin{array}{l}\text { Strong positive } \\
\text { correlation with urban } \\
\text { population scale }\end{array}$} \\
\hline & $\mathrm{p}$ & 0.003 & \\
\hline \multirow{2}{*}{$\begin{array}{l}\text { Average daily } \\
\text { growth rate of } \\
\text { confirmed } \\
\text { cases }\end{array}$} & $\mathrm{r}$ & $0.665^{* *}$ & \multirow{2}{*}{$\begin{array}{l}\text { Strong positive } \\
\text { correlation with urban } \\
\text { population scale }\end{array}$} \\
\hline & $\mathrm{p}$ & 0.005 & \\
\hline
\end{tabular}

\subsection{Epidemic and traffic accessibility}

The correlation analysis results between epidemic development and traffic accessibility are shown in Fig. 3 and Table. 4. According to the analysis, there is a moderate correlation between the number of confirmed cases and the traffic accessibility, and there is a strong positive correlation between the epidemic spread rate and the traffic accessibility. Overall, the higher the traffic accessibility, the more confirmed cases, the greater average daily growth rate, the faster the spread of the epidemic.
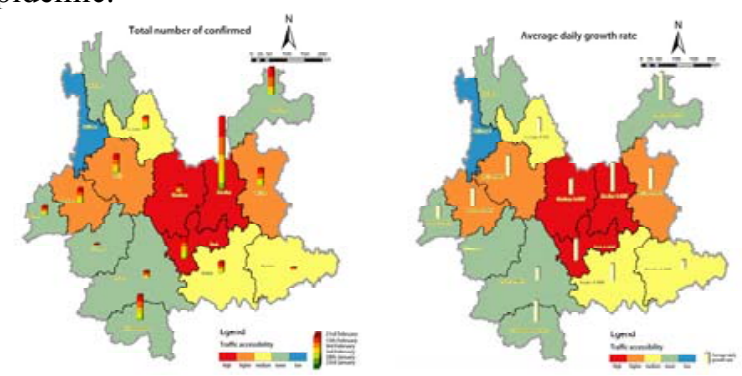

Fig. 3 Distribution of epidemic and traffic accessibility

Table.4 Correlation between Epidemic Development and Traffic Accessibility

\begin{tabular}{|c|c|c|c|}
\hline & & $\begin{array}{c}\text { Traffic } \\
\text { accessibility }\end{array}$ & Results \\
\hline \multirow{2}{*}{$\begin{array}{l}\text { Cumulative } \\
\text { confirmed } \\
\text { cases }\end{array}$} & $\mathrm{r}$ & $0.524^{*}$ & \multirow{2}{*}{$\begin{array}{l}\text { moderate positive } \\
\text { correlation with } \\
\text { traffic accessibility }\end{array}$} \\
\hline & $\mathrm{p}$ & 0.037 & \\
\hline \multirow{2}{*}{$\begin{array}{l}\text { Average } \\
\text { daily growth } \\
\text { rate of } \\
\text { confirmed } \\
\text { cases }\end{array}$} & $\mathrm{r}$ & $0.688^{* *}$ & \multirow[b]{2}{*}{$\begin{array}{l}\text { Strong positive } \\
\text { correlation } \\
\text { between traffic } \\
\text { accessibility }\end{array}$} \\
\hline & $\mathrm{p}$ & 0.003 & \\
\hline
\end{tabular}

\subsection{Epidemic and tourism destination fever}

The correlation analysis results of epidemic development and tourism fever are shown in Fig. 4 and Table. 5. According to the analysis, There is a strong correlation between the number of confirmed cases and the tourism fever, and there is a strong positive correlation between the spread rate and tourism fever. Overall, the higher the tourism fever, the more confirmed cases, the larger the daily average growth rate, the faster the spread of the epidemic.
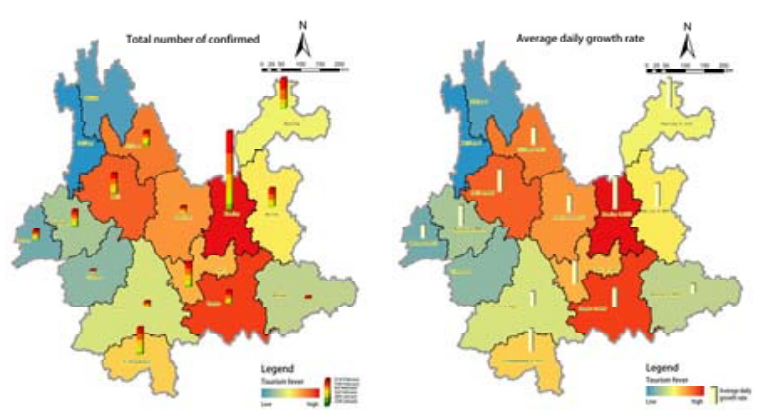

Fig. 4 Distribution of epidemic and tourism fever

Table. 5 Correlation between Epidemic Development and Tourism Fever

\begin{tabular}{|c|c|c|c|}
\hline & & $\begin{array}{l}\text { Tourism } \\
\text { fever }\end{array}$ & Results \\
\hline \multirow{2}{*}{$\begin{array}{c}\text { Cumulative } \\
\text { confirmed cases }\end{array}$} & $\mathrm{r}$ & $0.895^{* *}$ & \multirow{2}{*}{$\begin{array}{l}\text { Strong positive } \\
\text { correlation with } \\
\text { tourism fever }\end{array}$} \\
\hline & $\mathrm{p}$ & 0.000 & \\
\hline \multirow{2}{*}{$\begin{array}{l}\text { Average daily } \\
\text { growth rate of } \\
\text { confirmed cases }\end{array}$} & $\mathrm{r}$ & $0.626^{* *}$ & \multirow{2}{*}{$\begin{array}{l}\text { Strong positive } \\
\text { correlation with } \\
\text { tourism fever }\end{array}$} \\
\hline & $\mathrm{p}$ & 0.009 & \\
\hline
\end{tabular}

\subsection{Simulation analysis of epidemic situation development}

From the previous research, we can see that there is a certain correlation between epidemic development in Yunnan Province and the factors such as basin, urban scale, transportation, tourist destination fever and so on. Therefore, this section establishes a mathematical model to simulate and analyze the natural development trend of the epidemic in Yunnan province (No epidemic prevention measures are taken) and the development trend of the epidemic after adjusting the plan (Optimizing the urban system, transportation system, tourism pattern and public health and epidemic prevention facilities in the basin). The model adopts the classical "SEIR" model and divides the population into four categories: the Susceptibles, the Exposed, the Infected and the Recovered. The process of infection is as follows:

Susceptible $\Leftrightarrow B$ Exposed $\Leftrightarrow$ Infectious $\Leftrightarrow$ Recovered

This process can be expressed as ${ }^{[5]}$ :

$$
\begin{gathered}
\frac{d s}{d t}=-r \beta I S / N-r_{2} \beta_{2} E S / N \\
\frac{d E}{d t}=r \beta I S / N-\alpha E+r_{2} \beta_{2} E S / N \\
\frac{d I}{d t}=\alpha E-\gamma I \\
\frac{d R}{d t}=\gamma I
\end{gathered}
$$

"N"is the total number of people, and the coefficient is the probability of the transformation of the previous population into the next. The next iteration equation is as follows ${ }^{[5]}$ :

$$
\begin{gathered}
S_{n}=S_{n-1}-r \beta I_{n-1} S_{n-1} / N-r_{2} \beta_{2} E_{n-1} S_{n-1} / N \\
E_{n}=E_{n-1}+r \beta I_{n-1} S_{n-1} / N-\alpha E_{n-1} \\
+r_{2} \beta_{2} E_{n-1} S_{n-1} / N \\
I_{n}=I_{n-1}+\alpha E_{n-1}-\gamma I_{n-1}
\end{gathered}
$$




$$
R_{n}=R_{n-1}+\gamma I_{n-1}
$$

The concrete process is realized by Eclipse platform and using "java" language. According to the 2018 population statistics of Yunnan Province, we set the total number "N" to 48300000. First infected "I" to 1 . according to the speed of epidemic development, it is assumed that the number of infected persons exposed to health susceptibility is " $r=10$ ", the probability of infection after contact is " $\beta=0.6$ ", the number of latent persons exposed to health susceptibility is " $r_{2}=10$ ", the probability of infection after contact is " $\beta_{2}=0.6$ ", The probability of a latent being transformed into an infected person is " $\alpha=0.1$ ", and the probability of recovery after illness is " $\gamma=0.1$ ". The natural trend of epidemic situation in Yunnan Province is simulated (Fig. 5-1) .

Then we assume that after optimizing the urban pattern and tourism pattern of the basin, we can reduce the longdistance crowd flow and large-scale gathering, thus reducing the contact of people; The optimization of transportation system and the improvement of public health and epidemic prevention facilities can effectively shorten the time of medical treatment, improve the efficiency of medical treatment, and thus improve the recovery rate. The parameters were adjusted, the number of infected persons exposed to health susceptibility is " $r=5$ ", the number of latent persons exposed to health susceptibility is" $r_{2}=5$ ", the probability of recovery is" $\gamma=0.15 \%$, and the other parameters remained unchanged. The trend of the epidemic after the simulation and the planning adjustment is shown in Fig. $5-2$.

Compared with the two pictures, it can be found that after optimizing the urban system, transportation system, tourism pattern and public health and epidemic prevention facilities in the basin, the concentration of contact population is reduced, the recovery rate is increased, the number of people infected and latent is effectively reduced, and the time of virus infection is prolonged, which can effectively curb the development of epidemic situation.

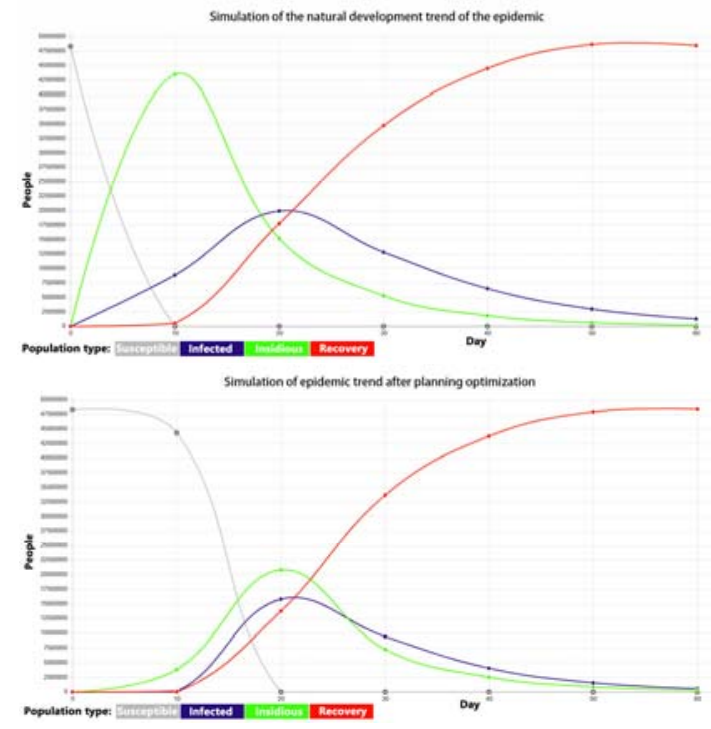

Fig. 5 Simulation of epidemic development

\subsection{Summary}

On the whole, there is a positive correlation between the epidemic development and basin, city scale, traffic accessibility, tourist destination fever and so on. The area of basin is larger, the city scale is larger, the traffic condition is better, the tourist fever is higher, the accumulative confirmed cases are relatively more, the case growth rate is faster, the epidemic situation is more serious. By improving the accessibility of transportation, optimizing the, optimizing the layout of regional public health facilities, strictly carrying out community isolation and unified living allocation, etc., it can provide assistance for the treatment of personnel and the living security after the disaster occurs. By optimizing the urban system, transportation system, tourism pattern and public health and epidemic prevention facilities in the basin, we can reduce the crowd gathering, reduce the crowd contact rate, and effectively curb the development of the epidemic situation.

\section{Suggestions on the planning of plateau basin under the influence of epidemic situation}

At present, the most effective and direct way to prevent and control the epidemic situation is to isolate it to the greatest extent ${ }^{[6]}$. In the land and space planning, on the one hand, it should be conducive to blocking the development of the epidemic situation. On the other hand, it should be conducive to ensuring the rescue of personnel and the basic life operation during the disaster. The transmission of the novel coronavirus pneumonia virus has special characteristics in the special geographical environment of the Yunnan plateau basin, so countermeasures for this particularity should be proposed.

\subsection{Overall planning of basins in the whole province}

(1) Basin coordination system. The basin of Yunnan province carries the layout of urban and rural residential, with the basically basin urban system. Its special geographical environment and relatively backward development stage decide that the unbalanced urban development roads should be taken in different areas ${ }^{[7]}$. The urban system relying on the basin system changes from "homogeneous dispersion" to "centralized trend" and finally to "aggregation equilibrium". The central Yunnan town group works as the main form, while the characteristic functions of regional key cities and towns and the radiation and driving role of key watersheds are highlighted. Then, the urbanization layout of the whole province could be optimized, to promote the coordinated development of cities and towns at all levels ${ }^{[8]}$, and to form a systematic development pattern of "Central Yunnan Urban Agglomeration + key river basins + key towns + characteristic towns + Beautiful Villages" (Fig. 6 and Fig. 7). From the perspective of epidemic prevention and control, it is also conducive to the layout of major public health facilities, relying on regional central towns. 


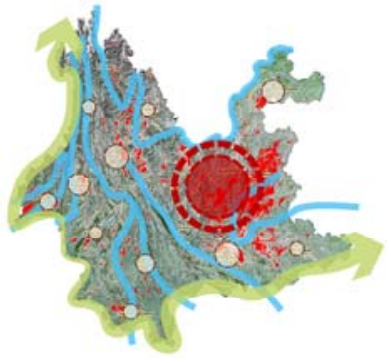

Fig. 6 The diagram of system coordination in basin of Yunnan province

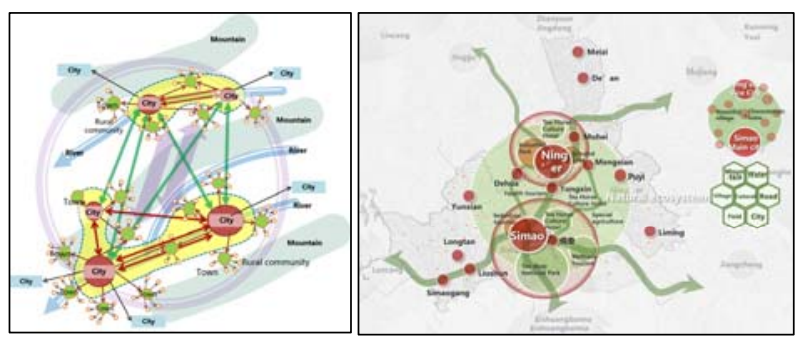

Fig. 7 Spatial Structure of Ideal Basin

(2) The whole area tourism system. The development and distribution of the epidemic situation is highly positively correlated with the popularity of scenic spots, which also reflects that Yunnan's tourism is still in the stage of relying on the key scenic spots. The characteristics are that the key scenic spots are overcrowded, while other scenic spots are sparsely developed. Taking the epidemic situation as a new starting point, grasping the transformation and upgrading strategy of "healthy living destination, relying on the diversity advantages of ecology, nationality and border areas, taking the whole area tourism as the starting point, and integrating the dimensions of panoramic, full-time, whole industry, the whole people to plan, the whole Yunnan should be constructed as a scenic area.

(3) Transportation optimization. Restricted by the plateau geographical environment, Yunnan's traffic development has been lagging behind the whole country. But this does not mean that the traffic in Yunnan can not be improved. From the perspective of epidemic prevention and control, the convenient comprehensive transportation system is also conducive to the first time to implement treatment for personnel and organize the transportation of materials. Based on the research on the distribution relationship between traffic path, traffic circle, traffic ray and basin of Yunnan Plateau, Yunnan's traffic improvement is actually clear ${ }^{[9]}$ (Fig. 8).

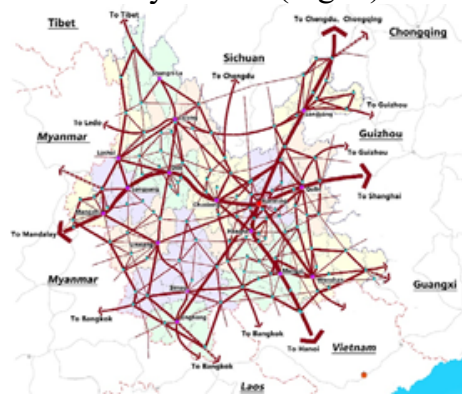

Fig. 8 Layout plan for integrated traffic zones of Yunnan province
(4) Overall layout of major regional public health and disaster prevention facilities. It is impossible and unnecessary for Yunnan to realize the equalized layout of major public health and disaster prevention facilities. On the basis of improving the traffic conditions, it is an economically feasible and effective scheme to lay out regional public health facilities relying on the urban agglomeration, key river basins and key towns in Central Yunnan Province, which is also conducive to the realization of "regional reception and centralized diagnosis and treatment"[10]. For example, the respiratory regional medical centers are constructed in Dianzhong, Honghe, Pu'er and Dali. At the same time, on the basis of adapting to the distribution of urban population, it is necessary to optimize the spatial layout of urban internal public health facilities and improve the supporting standards of facilities. Finally, urban public health and safety emergency management information platform should be established.

\subsection{Community of life in basin}

(1) To build a community of mountains, rivers, forests, fields, lakes and grasses. The basin of Yunnan Plateau embodies the natural law of the life community of mountains, rivers, forests, fields, lakes and grasses (Fig. 9). The outbreak of the epidemic has a lot to do with the fact that human beings have not respected the natural laws for a long time. The focus of basin governance should be on the control of natural resources use, and ecological restoration must follow the natural laws ${ }^{[11]}$. The systematic management of mountains, rivers, forests, fields, lakes and grasses should be emphasized. At the same time, the harmonious relationship between human and nature, urban and rural development, production and living ecology should be coordinated, to improve the human settlement environment in basins.

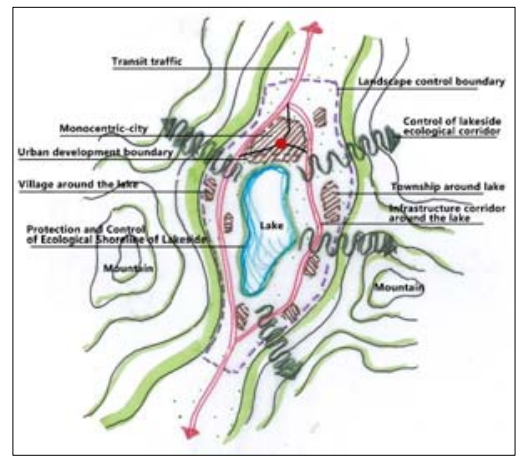

Fig. 9 The diagram of the life community in the basin

(2) To balance the production, living and ecology spaces and strictly control land use. The balance of "production, living and ecology spaces" is particularly important in the independent geographical units of the plateau basin. The key point of production space is to protect the basic farmland in the basin and retain the rural scenery. The focus of living space is to optimize the layout of urban system in the region and build high-quality living space. It is necessary to further improve the security and protection function of living space ${ }^{[12]}$ and improve the supporting facilities of living circle. The key point of 
ecological space is to protect the biodiversity space of plateau lakes, rivers and wetlands, display Colorful Yunnan, and improve the quality and stability of the ecosystem.

(3) Zoning and strategically delimiting blank areas in land use control. Due to the relatively independent geographical pattern of the plateau basin, the epidemic situation is easy to spread. Timely establishment of spatial isolation to build a safety barrier is an indispensable key link ${ }^{[13]}$. Based on the enlightenment of the construction of "Huoshen mountain" and "Leishen mountain", it is necessary to strategically delimit a certain range of blank land in the territorial spatial zoning. Combined with urban development, it is necessary to replace the unused land use functions according to the needs, coordinate the unexpected major events and major projects, reserve the space to deal with emergencies, and deal with the impact of major technological changes on urban spatial structure and land benefits, and to further promote the modernization of space governance capacity.

\subsection{Planning of life circle in plateau basin}

(1) Build "Online + offline" life circle. Under the influence of epidemic situation, the most direct and effective means of prevention and control is to reduce contact. Under the condition of ensuring basic life, the main means should be to reduce the travel distance of purchasing living materials, and take contactless distribution. Key cities and towns should build and improve the "Online + offline" life circle, refer to Suning's "1-hour scene life circle", Hemaxiansheng's "3-kilometer distribution" mode and Jingdong's "one-hour home delivery" mode, which can make up for the defects of the offline life circle service.

(2) Improving the 5-minute life circle on the county level. To strengthen the coverage of life circle facilities at the county, town and rural levels, combined with the geographical characteristics of the plateau basin, the 5minute life circle should be taken as the most basic unit, to provide necessities for life, and provide small convenience services such as small shops (grocery stores), vegetable shops, elderly rehabilitation, preschool education, sports venues, cultural places, etc., and to form a community life center. The 10 minute life circle should provide high-quality medical (pharmacy, outpatient), primary school, business, bus station, sports venues and other basic public service facilities. The 15 minute life circle, should provide the family care service center, township health center, compulsory education standardization school, cultural stadium, town park square, convenience supermarket and other inclusive daily life services, forming a neighborhood center. According to the characteristics of large dispersion and small agglomeration of urban and rural residential areas in the basin of Yunnan Province, and affected by geographical conditions and traffic conditions, 30 minute life circle should be added. Residents can enjoy high-quality medical services, high school and vocational and technical education, cultural and sports center, business complex, innovation and entrepreneurship service center, social governance center, and high-quality medical care service and other high-level comprehensive convenience services in 30 minutes (about 20-30 km) of driving (Fig. 10).

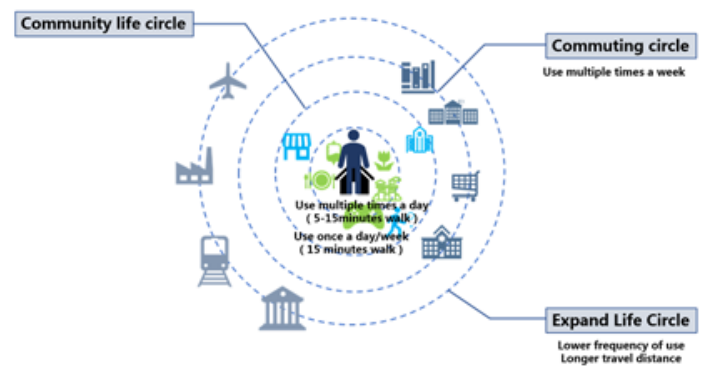

Fig. 10: The diagram of supporting life circle in basin

\subsection{Improvement of governance level and quality}

According to the definition of resilient city to "timely resist, absorb, adapt quickly and make effective response"[14], when a disaster occurs, urban residents, enterprises and infrastructure should be able to resist, adapt and recover quickly, which requires our government, social organizations and individuals to be in a highly unified governance system ${ }^{[15]}$. It can not only quickly mobilize the "hardware system" including public health, infrastructure and other emergency space, but also organize "software" systems such as personnel, funds and information to realize rapid response ${ }^{[16]}$. It includes reconstruction of regional basin community village group governance system, improvement of network management mechanism and strengthening of emergency publicity and drill system construction.

\section{Conclusion}

Through the analysis of large data space, the coronavirus epidemic situation is closely related to the spatial pattern of the Yunnan plateau basin. The special geographical environment also makes the epidemic prevention and control with special features. Taking this epidemic situation as an opportunity, based on the characteristics of the plateau basin, the concept of safety should be established. Focusing on comprehensive management, the land space planning of plateau basin highlights the improvement of comprehensive disaster prevention related content. Focusing on the regional basin community and governance level, the epidemic prevention, treatment and living security of disaster personnel should be highlighted, to implement systematic planning, and comprehensively improve the plateau basin in Yunnan province disaster emergency prevention and control level, and to create a high-quality living environment.

\section{Acknowledgements}

The research was supported by Science Research Subject of Yunnan Design Institute Group Co., Ltd.: Research on Classification of Land and Space in Yunnan Province (NO. S2019017); Research on Division and Classification method of Land and Space Planning in Yunnan Province (NO. NS202002). 


\section{References}

1. Chao Liu. Urban Scale and Density from the Perspective of "COVID-19" epidemic.- National Carpenter City ( 2020)

2. Yunnan Provincial Health Committee. Status of "COVID-19" epidemic in Yunnan Province as of 24:00 23rd February (2020)

3. Shaoyu Tong, Yongsen Chen. Study on Basins in Yunnan.- publishers of Yunnan University( 2007)

4. Jianyong Zhang, Ran Gao, Jun Hu. et al. Application comparison of grey correlation degree and Pearson correlation coefficient.- Journal of Chi feng University (Natural Science Edition) 30(21): 12(2014)

5. Zhihu. You can resist pneumonia at home! Play with "SEIR" infectious disease model(2020)

6. National Health Commission. Diagnosis and treatment of "COVID-19" (trial version 6)(2020)

7. Zhigang Luo. From urban system to national spata.publishers of Tongji University(2015)

8. Shaowen Zhang. Traffic Corridor Planning and study of the Yunnan urban system.- Yunnan Science and Technology Press(2009)

9. Ming Lu. Great stat needs bigger city.- Shanghai People Press(2018)

10. Xinan Fei, Wenchao Lu, Lin Li. The Way to Explore Resilient Cities.- Wuhan University Press(2017)

11. Ziqian Shi, Lu Zhang, Rrong Zeng. Low Carbon city development in Yunnan Province.- Planners(2011)

12. Ya Li, Guofang Zhai. Study on Assessment and Promotion Strategy of Urban Disaster Resilience in China.- Planners(2017)

13. Yan Yan. How does the construction of spatial planning system.- China Natural Resources News.(2020)

14. Minxing Yang, Bo Huang, Cui Zhong. et al. Review and Prospect: urban disaster resilience.- Urban Planning Forum(2016)

15. Ziqian Shi, Zhenyu Che, Chunfang Wang. Improvement of Urban space govemance rights in Dali city.- Planners(2016)

16. Yuxin Wu. Vulnerability of Big Cities: Resilient Cities Facing the "Black Swan Event"- Hangzhou City Research Center(2020) 